\title{
Comparative analysis of performance of Andhra Pradesh seeds corporation vs. private seed companies in Chittoor district
}

\author{
S. TEJ KIRAN AND T. V. NEELAKANTA SASTRY
}

Received : 02.12.2016; Revised : 09.03.2017; Accepted : 22.03.2017

\begin{abstract}
Seeds form the crucial input of agriculture. A sound seed sector in terms of quality and quantity can only support the agriculture sector of a huge country like India. Although, the AP seeds corporation is running with profits, the demand for further strengthening and expansion of the corporation has been increasing. In order to further compete with other competitors in producing quality seeds, it has to be alert and improve in all the aspects of seed production, distribution, marketing etc. SWOT analysis is a strategic planning method used to evaluate the strengths, weaknesses, opportunities and threats involved in a project or in a business venture. The objective of the research is to evaluate the performance of AP seeds vs. the private seed companies in Chittoor district of Andhra Pradesh through SWOT analysis and to develop a strategy for effective functioning of the organization. With consistence performance in all functional areas of the corporation, endeavor is to make AP seeds a benchmark seed company with the best of research, innovation and product development.
\end{abstract}

KEY WORDS : Andhra Pradesh seed industry, AP seeds corporation, SWOT analysis, Strengths, Weaknesses, Opportunities, Threats

How to cite this paper : Kiran, S. Tej and Sastry, T.V. Neelakanta (2017). Comparative analysis of performance of Andhra Pradesh seeds corporation vs. private seed companies in Chittoor district. Internat. J. Com. \& Bus. Manage, 10(1) : 34-37, DOI: 10.15740/HAS/ IJCBM/10.1/34-37. S.V. Agricultural College, Acharya N.G. Ranga Agricultural University, TIRUPATHI (A.P.) INDIA

Authors' affiliations:

T.V. NEELAKANTA SASTRY, Department of Agricultural Business Management, S.V. Agricultural College, Acharya N.G. Ranga Agricultural University, TIRUPATHI (A.P.) INDIA 